\title{
Basic principles of constructing a convergence model for managing innovative development of the economic and social system
}

\author{
Inna Geraskina ${ }^{1 *}$, and Alexander Petrov ${ }^{1}$ \\ ${ }^{1}$ Saint Petersburg State University of Architecture and Civil Engineering, Faculty of Economics and \\ Management, 190005 2-ya Krasnoarmeiskaya st. 4, Russian Federation
}

\begin{abstract}
Basic principles of constructing a convergence model for managing innovative development of the economic and social system are presented in the paper. The conceptual feature is accounting of system regularities and basic properties of the controlled object. The convergence model is focused on forming a synergetic potential of the economic and social system creating the sensitivity and its adequate reaction to synchronous and multiway managerial influence for development as per the special innovation vector. The model proposed by the authors is based on the collective effect of components (organized, information, production and intellectual) of the management system, determination of spatial-time position of the studied object, affected areas, control parameters and an interference value for stability and ability for changing of social and economic system over to the innovation trend. It was detected that its evolutionary dynamics is determined by the key factors: the existence of limits, the constant striving for the growth and hysteresis. High-priority problems of establishment were designed, and they consist in the modeling and forecasting the organization and management innovations and in arrangement of conditions for transfer to a qualitatively new trend that meets the requirements of the strategic plan.
\end{abstract}

The study of principal trends for development of the social and economic system (SES) and the environment being subject to systemic changes points to the necessity to improve the management model and system, arrangement of new requirements and approaches to the management. The key features for transformation of the economy and society actuating the activities on modernization of the existing management system are the following:

- scientific and technical progress and the necessity to form the intellectually creative, innovative type of the economy;

- objective globalization processes for creation of unified global system of management and public relations;

- limitation and degradation of resources aimed at finding ways to transition to the energy-resource efficient processes and technologies (sustainable development);

- hyper competition in the world market and high rate of renewal of product assortments, product differentiation where marketing and service functions make the greatest contribution to the creation of new cost and value;

- a high level of system consistency and exponential growth in data amount required for analysis and adoption of constructive managerial decisions;

*Corresponding author: geraskina82@mail.ru 
- system dynamics, complication of the business environment and processes in terms of technical improvement of production, organization of labor and management.

The interconnectedness of these factors significantly influences the strategic benchmarks of economic entities. Against this background, the underlying theories are ineffective, and the conventional models that previously allowed predicting and controlling the business require the replacement with more systematic lateral thinking. The investigations of endogenous regularities, sensitivity zones and structural dynamics effects on the SES development trends are actualized. The application of synergetics and dissipative structure theories to the management of complex systems allows determining a degree of human impact on the SES development as from the points of certain parameters of order, force, magnitude and time of control actions [1,2].

The conservative approaches that do not take into account the natural ways of evolution (attractors) immanently inherent in the managed system are ineffective from the point of the dialogue of innovative SES development. The V.D. Ayurov's point of view impresses; he believes that it is not inadvisable to control dissipative systems subjectively, since the control actions when imposing the functioning modes being not peculiar to it harm it only, and they are rejected [3].

The opinion of Professor B.L. Kuznetsov is interesting. He considers that the local subsystems of synergetic management are fundamentally different from classical analogues, since they use autocatalysis, auto regression, autocorrelation, coherence, amplification combinatorics of system-forming factors so that the process of innovation origin from the flicker quantum of scientific idea to the technological cluster is a single process, coordinated in space and time, combined by the single functional - efficiency and a single business mechanism [4].

The analysis of the long-term success of American companies ("Sony", "3M", "Wal Mart", "Walt Disney", "Boeing", "Hewlett-Parkard", etc.) given by D. Collins and D. Porras in the paper "Constructed forever" (2002) allowed to draw the following conclusion: deep development mechanisms in the absence of systemic exposition of the concept of advanced corporations prosperity have a fabulous similarity in the principles of management that have formed over a long period of time and have become the basis for progress stimulation: a) it is necessary to start a business with the desire to build a company but not to earn money; b) the driving force is aiming for a set of goals, including profit; c) to recede from a reasoned strategic plan for the benefit of non-standard solutions; d) move cautiously forward, catching and using special opportunities; e) a development benchmark is ideology reflecting the goals and causes of the organization existence [5].

The managers should understand the impossibility of accounting all options to predict the SES behavior. In case of failures, it is necessary to use a crisis bailout plan to try to direct the process in the right direction with convergence of the management system elements.

Currently, not all leaders have synergistic thinking to consider the SES as a living organism capable of homeossatis and self-organization. This understanding gradually comes to researchers of complex systems, in whatever field of knowledge they work. In this respect Professor G. Haken is sure that the time for synergetic formation has come [6, 7].

The system-synergetic thinking, to our opinion, is identified with arguments about the complexity of the world order, responsibility and ambiguity of the results of managerial decisions, modeling and the relative unpredictability of innovations in the system, choice problems. The presupposition of convergence SES management is conceptualized in saving its liveness and achieving strategic indicators, which management systems shall be oriented at, irrespective of their organizational level.

The management system is determined by the subsystem of the larger system that ensures achieving the goals of the managed system (subsystem) by influencing the 
structure, processes, relationships and relationships between entities under conditions that are acceptable for the existence of the managed system. The convergence model of managing the SES innovative development is aimed at increasing the effectiveness of management impacts, integrity control, homeostasis, synergistic potential. The latter creates the sensitivity and adequate reaction of the SES under investigation to synchronous, multiposition managerial influences for the goals system development according to a certain vector. It is important to take into account the rate of development dynamics which is increasing while moving from the global development to the local one (the smaller the social and economic system scale and the sphere of activities under consideration are, the more fluctuations in the rates of their innovative development are). Accelerating innovative development leads to an adequate growth of the synergetic potential that is a system attribute formed as a result of intersubjective interactions and structural-institutional dynamics mainly due to intangible assets and complementary effects accompanied by increasing the system activity and entropy.

An important characteristic of SES is the combination of order and chaos, the synthesis of which in the concept of a dissipative structure is considered in two aspects: 1) the system "order" exists only due to the chaos introduced into the environment; the existence is maintained by the constant exchange of matter, energy and data with it; 2) due to the "order", the SES gains the ability to adequately respond to chaotic environmental impacts, while maintaining stability. As viewed from the synergetics, the chaos can generate a new order that arises spontaneously, "not forced" by some exogenous force. The fluctuations occurring in the SES can be amplified instead of attenuation, and the system self-organizes.

The convergence model of managing the SES innovative development is aimed at achieving self-regulation, self-management and self-organization. It is assumed that the state has the critical role in creating a positive environment for the SES innovative development (institutional conditions that mean the standards and rules that contribute to either surge or paralysis and decline in the synergistic potential of the system). On being the management entity, it objectifies the development goals and objectives, ensures their achievement and solution. The state in this status positively determines the direction, rates, business and financial support for innovative development. On the one hand, the conditions completeness of the latter is ensured by hysteresis, historical, cultural, technological and managerial experience and, on the other hand, by the existing mechanism that to the maximum liberates the creative potential of the SES.

Since the intellectual sphere is the main source of innovations, it is possible to influence the SES entities by introducing negative entropy, taking into account the basic properties to the maximum, which are revealed when monitoring the environment and the structure to implement reflexive control. The order parameters and the set of control variables for the purpose of the synergistic potential required for increasing the SES activity, achieving the bifurcation state and synergetic effects in the context of path dependency control can be identified in case of economic and mathematical modeling $[8,9]$.

Effective models of managing the SES innovative development shall be compared with the features of a country and territory, national economy state, specific goals and objectives solved at certain intervals, resource supply opportunities and industry specificity [10]. In this regard, the detailed understanding of the general regularities and features of development of the SES and its entities is actualized. The structure of this system shall include the basic components and interacting subsystems: organizational, information, production and intellectual. They are sensitive to the production perception by end users whose reactions are accounted in accordance with its content. The decision on transformation is formed only based on the set of the SES state characteristics and the processes occurring in the management system. 
The specialized tools and subsystems that provide real-time monitoring the state of the processes occurring in them, their analysis and identification of the prerequisites for innovative development shall be created as part of the SES management system. In particular, the information subsystem as a basic process platform provides the collection and regulation of primary data, ranking, assessment of their significance, utility and scope of application. The technological basis will be composed by the network information technologies without which the convergence management processes are not effective in the organizational subsystem that reflects the structure of SES elements interaction in terms of composition and capacity fixed in the form of structure-forming relations and documents. The problems in such priority areas as: innovative solutions, the quality of management processes, fluctuation signs identification, bifurcations and other synergetic effects will be erased in the intellectual subsystem, the set of computer knowledge engineering elements (artificial intelligence), professional knowledge and personnel experience on the basis of its intellectual properties. Due to the fact that the decisive role shall be given to the information technologies in all subsystems, the processes of self-organization foremost belong to the competence area of information management.

The convergence of the management system components means impossibility of their independent existence, configuration and formation: each version of one of them most effectively corresponds to certain versions of others; a change in one of them will require the reconfiguration of the others. Otherwise, the management system will be ineffective. Therefore, when formulating the tasks of self-organization, the SES shall take into account the interrelations between the subsystems and the nature of their interdependence (Table 1).

Table 1. The content of relations between subsystems of the system for managing the SES innovative development

\begin{tabular}{|c|c|}
\hline Relation & Function \\
\hline $\begin{array}{l}\text { "Intelligence - } \\
\text { Information" }\end{array}$ & $\begin{array}{l}\text { Updating the data content with more complete and valuable } \\
\text { information arising from the analysis of the existing experience. }\end{array}$ \\
\hline $\begin{array}{l}\text { "Information - } \\
\text { Intelligence" }\end{array}$ & $\begin{array}{l}\text { Formation of the information space, provision of personnel with the } \\
\text { information that increases in a level of its competence, development } \\
\text { of intelligence and accumulation of organization knowledge }\end{array}$ \\
\hline $\begin{array}{l}\text { "Intelligence - } \\
\text { Organization" }\end{array}$ & $\begin{array}{l}\text { Increase in the level of intellectuality (conciseness) of employees } \\
\text { interaction in the process of labor activity, management self- } \\
\text { organization }\end{array}$ \\
\hline $\begin{array}{l}\text { "Organization - } \\
\text { Intelligence" }\end{array}$ & $\begin{array}{l}\text { Organization of processes for collective analysis of problem } \\
\text { situations and information comprehension, assurance of group } \\
\text { decision making on the basis of knowledge exchange and raising the } \\
\text { level of individual and collective intellectual potential of the } \\
\text { organization on this basis }\end{array}$ \\
\hline $\begin{array}{l}\text { "Intelligence - } \\
\text { Production" }\end{array}$ & $\begin{array}{l}\text { Transfer of accumulated knowledge or intellectual potential to the } \\
\text { level of the main production and thereby increasing its efficiency, } \\
\text { competitiveness, openness and negative entropy of the production } \\
\text { subsystem }\end{array}$ \\
\hline $\begin{array}{l}\text { "Production - } \\
\text { Intelligence" }\end{array}$ & $\begin{array}{l}\text { Reflection of identified innovative production solutions in the form } \\
\text { of professional knowledge leading to an increase in the knowledge } \\
\text { based capital of the organization in the field of primary activity }\end{array}$ \\
\hline $\begin{array}{l}\text { "Information - } \\
\text { Organization" }\end{array}$ & $\begin{array}{l}\text { Filling of communication processes between the personnel, system } \\
\text { and environment, which allows forming efficient internal and } \\
\text { external organizational structures both exogenously and in the order } \\
\text { of self-organization }\end{array}$ \\
\hline
\end{tabular}




\begin{tabular}{|l|l|}
\hline $\begin{array}{l}\text { "Organization - } \\
\text { Information" }\end{array}$ & $\begin{array}{l}\text { Addition of the information domain of the organization by } \\
\text { presentation in the information structures (databases) of the } \\
\text { organizational solutions with assessments of their effectiveness in } \\
\text { the form of appropriate organizational records }\end{array}$ \\
\hline $\begin{array}{l}\text { "Information - } \\
\text { Production" }\end{array}$ & $\begin{array}{l}\text { Provision of the production with all the completeness of information } \\
\text { required for its effective operation and innovative development }\end{array}$ \\
\hline $\begin{array}{l}\text { "Production - } \\
\text { Information" }\end{array}$ & $\begin{array}{l}\text { Representation of indicators featuring the production process and the } \\
\text { conditions for its existence in the information structures of the } \\
\text { management system (databases) }\end{array}$ \\
\hline $\begin{array}{l}\text { "Organization - } \\
\text { Production" }\end{array}$ & $\begin{array}{l}\text { Formation of organization bases of production (organizational and } \\
\text { management documentation) taking into account specificity and } \\
\text { changing operation environment }\end{array}$ \\
\hline "Production- \\
Organization" & $\begin{array}{l}\text { Reflection in the organization provisions of the activity status } \\
\text { (organizational and management documentation) of peculiarities and } \\
\text { specific features of the production }\end{array}$ \\
\hline
\end{tabular}

Modification of the state of any element(s) violates the settings of the entire system and requires managerial influence towards the formation of their new harmonious coordination (combination). A value of the quantitative elements (subsystems) transformations of the system and the relations between them can become a prerequisite for a synergistic effect provided that they are harmoniously combined. If the dynamics deteriorates the quality and exceeds a certain permissible limit, then the system properties change in principle and the previous settings no longer solve the above mentioned problems. Accordingly, it is necessary to make a decision to change the composition, structure and organization of the components of the SES management system.

The convergence model of managing the SES innovative development changes the management nature: from coercion of the management object to a new state, before creating favorable conditions for achieving a natural, targeted order. It is important to take into account that system imbalances can destroy the system integrity provided that: 1) at extreme nonlinearity, a hard resonance breaks it, while unlimited openness dissolves it in the external environment according to the entropic equilibrium principle; 2) when the nonlinearity is softened, the feedback is weakened, and its excessive closeness leads to entropy increase. That is, the organization and management innovations shall be aimed not only at the management improvement, but also at creation of favorable conditions for the possibility of achieving an innovative development trajectory.

During the discussion of any modernization project, the following questions: "Where to start?" and "What shall be the priority steps for modernization?" always take place. If there is no well-defined algorithm for obtaining the synergistic effects, many researchers propose a "trial and error" method based on extrapolation of actions, forecasting, experience and synergetic thinking of the leader who sets the rational goals for the organization.

In this case, the process of understanding the strategic goals and objectives for the SES striving for self-organization, stability and innovation is fundamental. Short-term benefits (for example, welfare and high profits from productive activities) in the long term may result in SES functioning deterioration. Many of the well-known global problems (climate change, depletion of oil resources, exponential population growth, agricultural land degradation, freshwater deficit, etc.) and their consequences have already been evident. According to D. Medouz and J. Randers, the environmental load continues to grow despite the development of technologies and the efforts of public organizations. The scientists described this in the report "Limits of Growth" (1972) prepared under the project of the Club of Rome "Problems of Humanity". Even then they noted that humanity "has gone beyond the limits and is in an unstable field" due to the consumer attitude to the nature. To 
reduce the impact on the environment and return to an acceptable level, personal and social values shall be changed and that will take a long time [11].

According to the concept of sustainable development, the main problem lies in ensuring the balanced SES development with the imperative to prevent a catastrophe and society orientation towards self-maintenance based on the convergence models and approaches to management. Technical advance, innovations, sustainable development, formation of competitiveness and marketing management are certainly necessary, but not sufficient, since the development is the result of non-linear interactions.

The convergence model of managing the SES innovative development can serve as a powerful management foundation to search and support the self-organizing trends. In practice, this is associated with risks caused not only by the desire to get into the future that is absent in the possibilities spectrum, but also by the inability to detect the development path in the presence of the possibilities spectrum. In the first case, there is the danger of aggressive management when the goal is achieved by reorganizing the managed system that involves a continuous flow of significant costs and efforts to keep the SES on an unstable way. The balanced management supposes an impact on the social and economic system to achieve the desired and immanently inherent states with the synergistic effects through the consistent implementation of the functions and mechanisms in the SES to form the organizational survival basis in turbulence, as well as institutional forms and relationships that stimulate and develop the ability to an innovate component.

Therefore, the methodological provisions of the convergence model of managing the SES innovative development are as follows:

- its heterogeneous structure covers heterogeneous elements - technology, organization, ecology, mentality, psychology, politics, security, all kinds of resources and their interrelations;

- it is focused on a positive synergistic effect through the principles and influence the control parameters for analyzing the phase space and identifying inherently inherent development paths;

- its fixed management parameters established in the space-time and resource coordinates take into account the boundaries of the balanced approach, adequate to the mission, goals, potential, opportunities and threats of the environment;

- its unique architecture (due to the absence of the standard algorithm of actions and orientation to a creative approach) is specified by a set of development elements investment, intellectual, technological and product resources forming the synergetic potential;

- the task of SES management structures is the modeling and forecasting of development trends that form the positive feedbacks and create the prerequisites for its transition to a new quality meeting the requirements and the image of the "future";

- the SES development path can be set by the systems of differential equations with the aim of predicting and scientific substantiating the programs to be developed which shall be realistic and realizable. In a number of scientific papers, the authors demonstrated the practice of modeling the trend for development of the most important subsystems of the national economy based on the second- and third-order differential equations [9].

First of all, the stable innovative SES development shall focus on its internal intrinsically characterized self-organization and its own laws of evolution which shall be taken into account and improved in the proper focus. A development vector cannot be imposed on the complex systems, firstly, it is necessary to understand their own trends (natural attractors), and then output them with resonant, topologically verified effects to the path of evolutionary formation.

An important factor in the SES self-organization is the national idea that expresses the symbolic capital of the culture in the information space. Activation of the innovative 
development of Russia's economy is possible in conditions of coherent management due to the positive synergetic effects in the systems aimed at a large-scale innovative breakthrough and development of resources of the new technological order. However, the following dilemma arises: "How to manage "without managing"?", "How to force the SES to one of the own and favorable development paths with a small resonant impact?", "How to ensure self-controlled and sustainable development?". The implementation of the principles, approaches, tools and the business mechanism of the balanced SES development system will allow full using the existing system potential and obtaining the positive synergetic effect.

Finally, the following important conclusions shall be drawn.

Sustainable innovative development of the SES assumes the formation of a synergistic potential represented by a systemic property formed as a result of inter-entity interactions and structural-institutional dynamics, mainly, due to intangible assets and complementary effects accompanied by increasing the level of its activity and entropy which provide the sensitivity and adequate reaction of its subjects and relations in the system to small exogenous (mainly, management) and endogenous effects to develop the economic system by a specific vector of goals and achievement of strategic indicators.

To provide the appearance of the system-synergetic effects in SES and its subsystems, it is required to have the following basic conditions: nonlinearity, openness, dynamism, organization, heterogeneity, freedom of economic activity, coherence, working feedback and functional correspondence of elements, synchronization of flowing processes and processes, efficacy of system response to signals from the environment. The synergistic effect in SES is the result of the coherent action of its heterogeneous composite components that causes endogenous transformations and qualitative changes in the system state under resonant exogenous effects $[2,9]$.

The management of SES innovative development means modeling and timely response to transformation of external and internal conditions which means identification of resonant zones where the consequences scale is determined by the force of their impact and consistency with the endogenous properties. Innovative development is determined by the basic parameters - the degree of internal ordering and the strength of the external control action. A synergetic effect occurs when the positive feedbacks operates within the economic system and directed to it from the outside.

Thus, the meaning of the stated prerogative of actions is not to replace the concept and model, but in the harmonious, peak effective use of raw and innovative factors available in the national SES. It is required to change the concepts in the evolution. Movement to the adopted social model shall be step-by-step, synchronous and parallel-sequential. This methodological approach in the light of the strategy of SES transfer to the innovative development path is determined, firstly, by the interrelations, interdependence and interpenetration of social phenomena, and, secondly, by the need of accounting the inertness of the system itself, i.e., time during which the desired state is achieved.

\section{References}

1. I.N. Geraskina, Economic analysis: theory and practices, 16 (2)(2017)

2. I.N. Geraskina, Management of innovative development of economic and social systems (Research Institute of the Humanities by the Government of the Republic of Mordovia, Saransk, 2017)

3. V.D. Ayurov, Economy synergetics (Publishing House of Moscow State Mining University, Moscow, 2005) 
4. B.L. Kuznetsov, S.B. Kuznetsova, Theory of synergistic market (Publishing House of Kama State Academy of Engineering and Economics, Naberezhnye Chelny, 2006)

5. J.C. Collins, J.I. Porras, Built to Last. Successful Habits of Visionary Companies(Harper Collins Publishers, New York, 2002)

6. G.Haken, The secrets of nature. Synergetics: Theory of interaction (Institute of Computer Sciences, Izhevsk-Moscow, 2003)

7. G.Haken, Hierarchy of variabilities in self-organizing systems and devices (Mir, Moscow, 1985)

8. G.G. Malinetsky, To build reality from fairytale... High technologies - Russia's way to the future (Publishing House URSS, Moscow, 2015)

9. I.N. Geraskina, A.V. Zatonskiy, A.A. Petrov, International Journal of Civil Engineering and Technology (IJCIET), 8 (10) (2017)

10. A.A. Akaev, S.Yu. Rumyantseva, A.I. Sarygulov, V.N. Sokolov, Structural-cyclic processes of economic dynamics (Publishing House of Polytechnic University, St. Petersburg, 2016)

11. D. Medouz, J. Randers, Growth limits. 30 years later (BINOM. Laboratory of Knowledge, Moscow, 2012) 